\title{
Molecular evidence for the hybrid origin of Potamogeton $\times$ subrufus Hagstr. (Potamogetonaceae)
}

\author{
Joanna Zalewska-Gałosz*, Dagmara Kwolek \\ Institute of Botany, Jagiellonian University, Kopernika 31, 31-501 Cracow, Poland
}

\begin{abstract}
Potamogeton $\times$ subrufus Hagstr. was described as a hybrid between $P$. lucens L. and P. nodosus Poir.; however, the taxon had not been widely accepted and regarded as conspecific with $P$. $\times$ fluitans Roth, the hybrid between $P$. lucens and P. natans L. The origin of $P$. $\times$ subrufus had been obscured till 2010, when, based on morpho-anatomical treatment, it was shown that $P$. $\times$ subrufus displays several characters consistently different from those of $P . \times f l u i t a n s$. Here we report a successful amplification and sequencing of nuclear ribosomal ITS1 region from a 115 year-old herbarium specimen of $P$. $\times s u b r u f u s$, collected in locus classicus by J. Baagöe and preserved in the Herbarium of the Institute of Botany, Jagiellonian University (KRA). Based on the additive polymorphism pattern expressed in the ITS1 sequences of $P$. $\times$ subrufus, we demonstrate that one of the parents of this hybrid was $P$. nodosus, as was claimed by Hagström.
\end{abstract}

Keywords: aquatic plants; cloning; hybridization; ITS1; molecular identification; Potamogeton; sequencing; taxonomy

\section{Introduction}

Interspecific hybridization is one of the important factors shaping Potamogeton diversity [1-3]. Although Potamogeton hybrids are mostly sterile, due to vegetative propagation they often create stable populations of high ecological significance [3]. Moreover, the hybrids are able to persist at a locality for even hundreds or thousands of years [4-6], what makes them an important component of local floras.

Potamogeton $\times$ subrufus Hagstr. was described as a hybrid between $P$. lucens L. and P. nodosus Poir. [1]. Subsequently, Potamogeton taxonomists had not generally accepted this taxon and usually regarded $P$. $\times$ subrufus as conspecific with fairly common and morphologically similar hybrid $P$. lucens $\times P$. natans, named $P . \times$ fluitans Roth [2,7]. Only recently, based on morpho-anatomical treatment of the original materials of $P$. $\times$ subrufus, it was shown that this taxon displays several, mainly anatomical characters different from those of $P$. $\times$ fluitans [6]. Although anatomical characters are highly informative for identification of some Potamogeton hybrids [8-10], modern taxonomy of the genus focuses in particular on the molecular assessment and unequivocal confirmation of the hybrid origin by means of the molecular tools [11-15]. Bearing in mind the controversy on the taxonomic status of $P$. $\times$ subrufus, a molecular evidence for the hybrid origin of this taxon is highly desirable. Therefore, the aim of this

\footnotetext{
*Corresponding author. Email: joanna.zalewska-galosz@uj.edu.pl
} Handling Editor: Krzysztof Spalik study is to analyze the molecular characters of the herbarium specimen of $P$. $\times$ subrufus collected in locus classicus, together with European broad-leaved Potamogeton species, which could have potentially served as its parental species, and to resolve the origin of the hybrid.

\section{Material and methods}

\section{Plant material used for molecular analysis}

DNA was extracted from one leaf taken from the specimen of $P$. $\times$ subrufus, collected by J. Baagöe in Jutland, in the river Gudenå (Denmark), on 1 August 1899 and preserved in the herbarium of the Institute of Botany, Jagiellonian University (KRA). Aliquot of DNA extracted from the specimen of $P$. $\times$ subrufus (KRA 91746) was deposited in the Institute of Botany, Jagiellonian University. As a reference for the analysis of the putative hybrid genotype, a comprehensive set of broad-leaved Potamogeton species representing potential parental taxa was included in the molecular analyses. Species were mostly represented by one to three samples collected from distant populations based on earlier observations that intraspecific sequence polymorphism was observed only exceptionally in the analyzed DNA regions of Potamogeton $[12,16]$. Fresh material was collected in the field and stored in small plastic tubes filled with silica gel. The origin of the sequenced Potamogeton samples is provided in our previous studies [12,17]. Taxonomic delimitation of species and taxa names followed Wiegleb and Kaplan [2], unless a more recent reference is cited. 


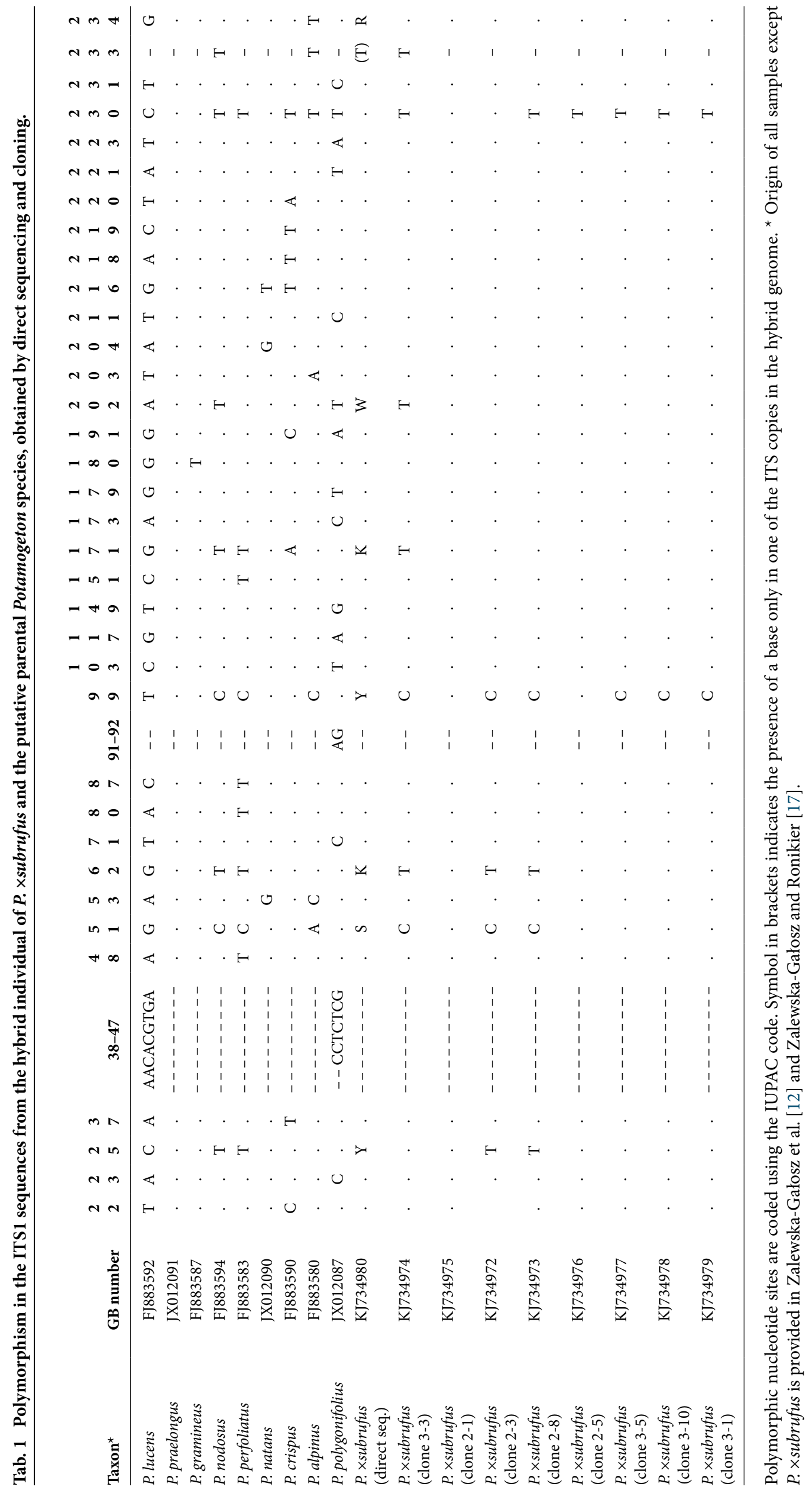




\section{DNA isolation, PCR amplification, sequencing and cloning}

DNA isolation, PCR amplification, direct sequencing of ITS1 and the sequence editing were done as described by Zalewska-Gałosz et al. [12]. ITS1 region was amplified using the primers ITS A and ITS C [18]. Additionally, the ITS1 region obtained from the type specimen of $P$. $\times$ subrufus was cloned to verify its additivity pattern, following the method described by Zalewska-Gałosz et al. [19]. The ITS1 sequences of $P$. $\times$ subrufus were submitted to GenBank under the numbers KJ734972-80.

\section{Phylogenetic analysis}

Phylogenetic relationships were estimated using MEGA version 5.0 [20]. The maximum likelihood (ML) method was performed with Jukes-Cantor substitution model [21], which was selected based on BIC (Bayesian information criterion). The tree with the highest log likelihood (-598.87) is shown. Bootstrap support values from 1000 replicates are shown next to the branches. Initial trees for the heuristic searches were obtained with neighbor-joining algorithm and a matrix of pairwise distances estimated using the maximum composite likelihood (MCL) approach. The tree was drawn to scale, with branch lengths estimated based on the number of substitutions per site using Jukes-Cantor model. The analysis involved 17 nucleotide sequences. There were a total of 234 positions in the final dataset.

\section{Results}

The DNA sample extracted from the herbarium specimen of Potamogeton $\times$ subrufus showed signs of degradation. Judging from the appearance of the total DNA in the agarose gel it contained mainly fragments shorter than 300 bp. It is not surprising therefore that all attempts to amplify the entire ITS region (ITS1, 5.8S, ITS2) were unsuccessful. Similarly, we were not able to obtain shorter fragments of ITS using the primers suggested by Blatter [18] as well as the sequence of cpDNA rpl32-trnL intergenic spacer despite using internal primers. The only sequence we have succeeded to amplify was ITS1. The fragment obtained by direct sequencing was 479 base pair long and covered entire ITS1 region and the beginning of the gene 5.8S. The sequence displayed an additive polymorphism at eight positions. Examination of the polymorphism pattern in these positions allowed indicating $P$. lucens/P. praelongus and P. nodosus as the parental taxa of $P$. $\times$ subrufus (Tab. 1). The chromatogram had a little baseline noise, what was probably caused by poor quality of DNA template $\left(\mathrm{A}_{260} / \mathrm{A}_{280}\right.$ ratio was 1.66) and could lead to misinterpretation; therefore, cloning of the ITS1 sequence was performed. Sequences of eight clones were obtained, each 320 base pair long. Clone 3-3 was identical with ITS 1 sequence of $P$. nodosus while clone 2-1 was identical with ITS1 sequence of $P$. lucens and P. praelongus (Tab. 1, Fig. 1). None of the other clones of $P$. $\times$ subrufus was identical with any sequence obtained from the Potamogeton species. Clones 2-3 and 2-8 had a chimeric character. The first part of these sequences, to the position 99 at the alignment, was identical with $P$. nodosus while the second part resembled $P$. lucens/P. praelongus, except the position 230 in the clone 2-8 (Tab. 1). The clone 2-5 was almost identical with $P$. lucens/P. praelongus sequence except the position 230, where it had $\mathrm{T}$ instead of $\mathrm{C}$ (Tab. 1). The clones 3-1, 3-5 and 3-10 were similar to the ITS1 sequences of $P$. lucens/P. praelongus except two positions: 99, where the clones had $\mathrm{C}$, and 230, where clones had T (Tab. 1). Because there is no differences in the ITS1 sequence between $P$. lucens and $P$. praelongus, it is impossible to determine which of these species served as an ITS ribotype donor for P. ×subrufus.

\section{Discussion}

Potamogeton $\times$ subrufus was described based on the specimens collected from two separate localities in Europe and North America over than a century ago [1]. European population of $P$. $\times$ subrufus in the Gudenå River in Denmark probably disappeared [22]. American locality was enigmatically described and difficult to locate. Therefore, despite that DNA extracted from herbarium materials is often poorquality, its examination was the only possibility for checking the molecular characteristics of this taxon.

The aim of the present study was to resolve the controversy whether $P$. $\times$ subrufus originated from the cross between $P$. lucens and $P$. natans or P. lucens and P. nodosus. We have found that one of the parents of $P . \times$ subrufus is $P$. nodosus and definitely not $P$. natans (Tab. 1, Fig. 1). Although the second parent could not be univocally identified based on the ITS1 sequences, the parentage of $P$. lucens is well supported by morphology of $P$. $\times$ subrufus. Potamogeton lucens is the only pondweed species that develops stipules with winged ridges. Narrowly winged ridges of stipules are also characteristic for $P$. $\times$ subrufus [6]. Also, P. ×subrufus alike $P$. lucens and $P$. nododsus has petiolate submersed leaves while $P$. praelongus and all of its hybrids develop sessile submersed leaves [1-3].

The present results, although limited due to degraded DNA extracted from an old herbarium specimen, supplement the previous morpho-anatomical treatment of $P$. $\times$ subrufus [6]. Finally, based on all available evidence, it can be stated that $P$. $\times$ subrufus is a hybrid of $P$. lucens and $P$. nodosus.

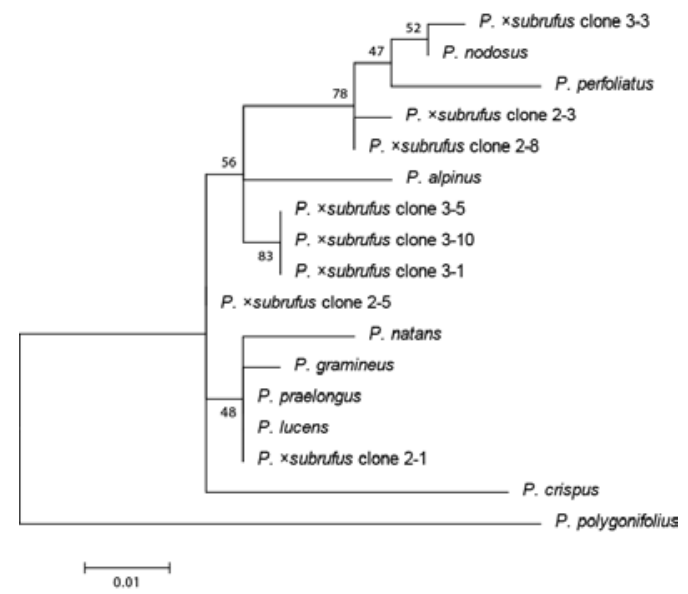

Fig. 1 Identification of the hybrid origin based on cloned ITS1 sequences inferred using maximum likelihood method with MEGA5. Bootstrap support values from 1000 replicates are shown next to the branches. Cloned hybrid sequences are numbered and their accession numbers are provided in Tab. 1. 


\section{Acknowledgments}

We would like to thank Dr. Wacław Bartoszek, curator of the Herbarium of the Institute of Botany, Jagiellonian University, for his permission for DNA extraction from the herbarium specimen. The research was financially supported by grant No. N N303 564439 from the Polish Ministry of Science and Higher Education.

\section{Authors' contributions}

The following declarations about authors' contributions to the research have been made: idea of study, research design, interpretation of the results, writing the manuscript: JZG; molecular analysis, results consulting, editing the manuscript: DK.

\section{References}

1. Hagström JO. Critical researches on the Potamogeton. K Sven Vetenskapsakademiens Handl. 1916;55:1-281.

2. Wiegleb G, Kaplan Z. An account of the species of Potamogeton L. (Potamogetonaceae). Folia Geobot. 1998;33:241-316.

3. Preston CD. Pondweeds of Great Britain and Ireland. London: Botanical Society of the British Isles; 1995. (BSBI Handbook No. 8).

4. Hollingsworth PM, Preston CD, Gornall RJ. Isozyme evidence for the parentage and multiple origins of Potamogeton $\times$ suecicus (P. pectinatus $\times$ P. filiformis, Potamogetonaceae). Plant Syst Evol. 1996;202(3-4):219-232. http://dx.doi.org/10.1007/BF00983384

5. King RA, Gornall RJ, Preston CD, Croft JM. Molecular confirmation of Potamogeton $\times$ bottnicus (P. pectinatus $\times P$. vaginatus, Potamogetonaceae) in Britain. Bot J Linn Soc. 2001;135(1):67-70. http://dx.doi. org/10.1111/j.1095-8339.2001.tb02370.x

6. Zalewska-Gałosz J. Potamogeton $\times$ subrufus Hagstr.: a neglected Potamogeton hybrid. Ann Bot Fenn. 2010;47(4):257-260. http:// dx.doi.org/10.5735/085.047.0402

7. Dandy JE, Taylor G. Studies of British Potamogetons - XVI $\times$ Potamogeton olivaceus (P. alpinus $\times$ P. crispus). J Bot Br Foreign Lond. 1942;80:117-120.

8. Wiegleb G. The importance of stem anatomical characters for the systematics of the genus Potamogeton L. Flora. 1990;184(3):197-208.

9. Kaplan Z. Potamogeton $\times$ fluitans (P. natans $\times$ P. lucens) in the Czech Republic. I. Morphology and anatomy. Preslia. 2001;73(4):333-340.

10. Zalewska-Gałosz J. Potamogeton $\times$ jutlandicus, a binominal for the hybrid between $P$. lucens and P. praelongus (Potamogetonaceae). Nord J Bot. 2011;29(4):473-476. http://dx.doi. org/10.1111/j.1756-1051.2011.01154.x

11. Kaplan Z, Fehrer J, Hellquist CB. New hybrid combinations revealed by molecular analysis: the unknown side of north american pondweed diversity (Potamogeton). Syst Bot. 2009;34(4):625-642. http://dx.doi. org/10.1600/036364409790139745

12. Zalewska-Gałosz J, Ronikier M, Kaplan Z. The first European record of Potamogeton $\times$ subobtusus identified using ITS and cpDNA sequence data. Preslia. 2009;81:281-292.

13. Zalewska-Gałosz J, Ronikier M. Are linear-leaved Potamogeton hybrids really so rare? Molecular evidence for multiple hybridizations between $P$. acutifolius and $P$. compressus in central Europe. Nord J Bot. 2010;28(3):257-261. http://dx.doi. org/10.1111/j.1756-1051.2010.00724.x

14. Zalewska-Gałosz J, Ronikier M. Potamogeton $\times$ maëmetsiae - a new hybrid of linear-leaved pondweeds from central Europe. Preslia. 2011;83(3):259-273.

15. Bobrov AA, Zalewska-Gałosz J, Chemeris EV. Potamogeton $\times$ clandestinus (P. crispus $\times$ P. natans, Potamogetonaceae), a new natural pondweed hybrid discovered in Europe. Phytotaxa. 2013;149(1):31. http://dx.doi.org/10.11646/phytotaxa.149.1.5

16. Kaplan Z, Fehrer J. Erroneous identities of Potamogeton hybrids corrected by molecular analysis of plants from type clones. Taxon. 2011;60(3):758-766.

17. Zalewska-Gałosz J, Ronikier M. Molecular evidence for two rare Potamogeton natans hybrids with reassessment of Potamogeton hybrid diversity in Poland. Aquat Bot. 2012;103:15-22. http://dx.doi. org/10.1016/j.aquabot.2012.05.005

18. Blattner FR. Direct amplification of the entire ITS region from poorly preserved plant material using recombinant PCR. BioTechniques. 1999;27(6):1180-1186.

19. Zalewska-Gałosz J, Jopek M, Ilnicki T. Hybridization in Batrachium group: controversial delimitation between heterophyllous Ranunculus penicillatus and the hybrid Ranunculus fluitans $\times$ R. peltatus. Aquat Bot. 2014 (in press). http://dx.doi.org/10.1016/j.aquabot.2014.03.002

20. Tamura K, Peterson D, Peterson N, Stecher G, Nei M, Kumar S. MEGA5: molecular evolutionary genetics analysis using maximum likelihood, evolutionary distance, and maximum parsimony methods. Mol Biol Evol. 2011;28(10):2731-2739. http://dx.doi.org/10.1093/ molbev/msr121

21. Jukes TH, Cantor CR. Evolution of protein molecules. In: Munro HN, editor. Mammalian protein metabolism. New York, NY: Academic Press; 1969. p. 21-132.

22. Kaplan Z, Fehrer J. Molecular identification of hybrids from a former hot spot of Potamogeton hybrid diversity. Aquat Bot. 2013;105:34-40. http://dx.doi.org/10.1016/j.aquabot.2012.11.002 